\title{
Adverbial, Descriptive Reciprocals
}

\author{
Barry Schein \\ University of Southern California
}

Reciprocity was a topic very much on the minds of New Yorkers in the midseventies. Fiengo \& Lasnik, Dougherty, Katz, and Langendoen worried, for example, that the state of mutual respect asserted in (1) implies warm feelings between any two family members, but the actions that these feelings lead to canand, in this example, must - fall short of every family member kneeling at every other family member's grave.

(1) The family members respected each other, and paid their respects at each other's funeral.

New Yorkers and non-New Yorkers alike had hoped that such variation in reciprocity's meaning could be resolved in terms of the two quantifiers that each and other stand for. Thus, each would be taken to quantify variously over individuals alone or over groups as in (2), and other to refer either to every one of the others or to some other or others:

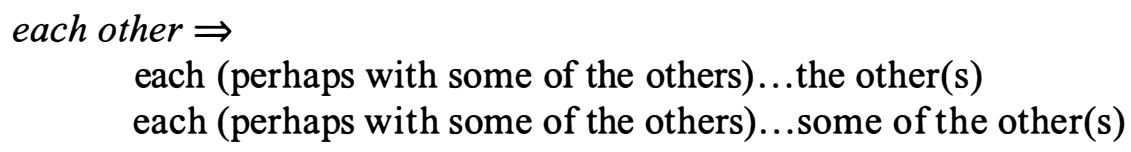

(Fiengo \& Lasnik 1973, Dougherty 1974, Langendoen 1978, L. Carlson 1982, Heim, Lasnik \& May 1991)

Fixing these parameters one way or another should obtain-so it was thoughtthe extant readings of reciprocal sentences. If it is true that the resources assumed in (2) are already attested in (3), where reciprocity is expressed plainly by two such quantifiers, one could hardly be faulted for hoping to find the same in (1) despite the reciprocal's more compact appearance.

(3) The family members waved good-bye, each to the others.

The family members waved good-bye, one to the other(s).

The family members waved good-bye, the one to the other(s).

The family members waved good-bye, each to another.

The family members waved good-bye, (the) one to another.

The family members waved good-bye, each saluting the others.

The family members waved good-bye, one saluting the other(s).

The family members waved good-bye, the one saluting the other(s). 
The family members waved good-bye, each saluting another.

The family members waved good-bye, (the) one saluting another.

I too would like to resolve reciprocals into familiar quantifiers, but some recent work raises an important objection to this project. Dalrymple, Kanazawa, Kim, Mchombo \& Peters (1998) revisit an interpretation of (4) observed earlier by Langendoen and remark that it discriminates between the circumstances depicted in (5) and (6):

(4) The freeway exits are spaced five miles from each other. (Dalrymple et al. 1998)
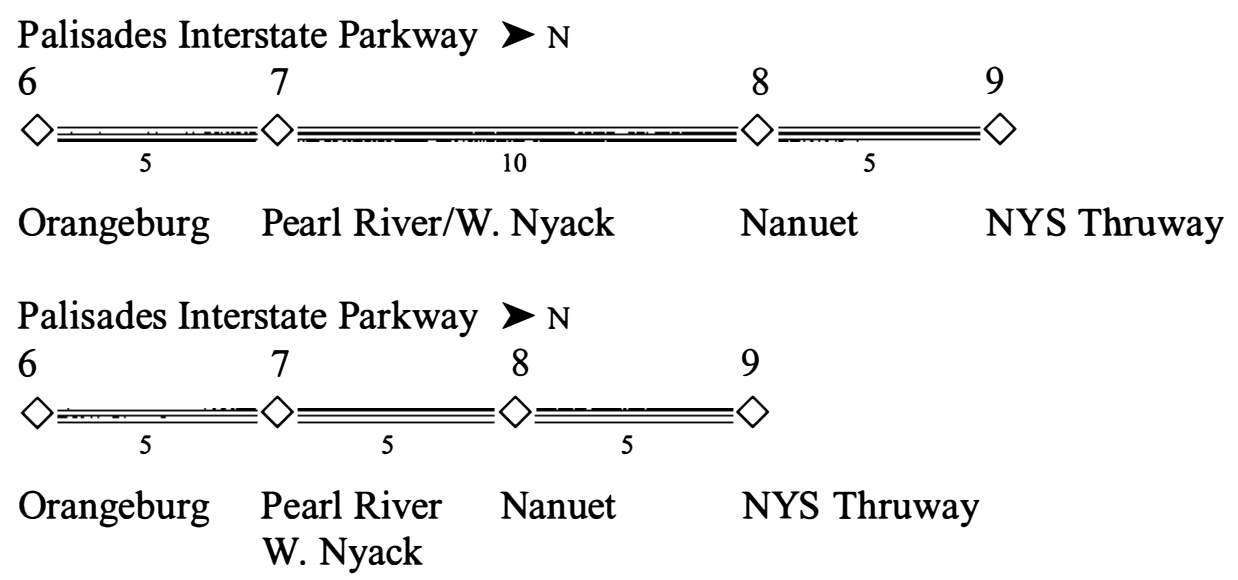

The sentence is true in (6) because each exit is five miles from the next, but false in (5) since Exit 7 is ten rather than five miles from Exit 8. Despite the various meanings schema (2) provides, the authors point out that it fails to provide the intended meaning of the reciprocal in (4). On the one hand, the sentence surely does not mean that every exit is five miles from every other exit. That would make it false in (6) and everywhere else where there are freeways. On the other hand, it suffices for weaker readings that every exit is five miles from some other exit, and this would mistakenly make sentence (4) true in (5): despite the ten miles that separate Exits 7 and 8, each is in fact five miles from an exit in the opposite direction.

Dalrymple et al. are correct that (4) shows a defect in (2) for the reasons given. To render the meaning of (4), they resort instead to a translation of the reciprocal each other as primitive and polyadic. The meaning of the reciprocal will require every freeway exit to be related to every other exit; but they are related not by the given relation $x$ is spaced five miles from $y$ but by its transitive closure. What that means is that it is enough in (6) that there is a chain of exits at intervals of five miles that connects Exit 6 to Exit 9 and likewise for any other two exits. No such chain connects Exit 6 to Exit 9 in (5) as there is also no such chain connecting Exits 7 and 8. Thus every pair of exits in (6) but not in (5) are related by the transitive closure of is-spaced-five-miles-from. 


$$
\begin{aligned}
& \text { Df. } \tau \mathrm{R} \text {, the transitive closure of } \mathrm{R},(\text { Boolos } 1985) \text { : } \\
& \left.\tau \mathrm{R} x y \leftrightarrow \forall U\left(\left(\forall x^{\prime}\left(\mathrm{R} x x^{\prime} \rightarrow U x^{\prime}\right) \& \forall z \forall z^{\prime}\left(\left(U z \& \mathrm{R} z z^{\prime}\right) \rightarrow U z^{\prime}\right)\right) \rightarrow U y\right)\right) \\
& \text { E.g., } x \tau(\text { is-a-parent-of) } y \leftrightarrow x \text { is an ancestor of } y .
\end{aligned}
$$

(8) Df. $\mathrm{R} \mid X$, the restriction of $\mathrm{R}$ to $X$. $\mathrm{R} \mid X x y \leftrightarrow(\mathrm{R} x y \& X x \& X y)$

$$
\text { each-other } \mathrm{R}(X) \leftrightarrow \forall x \forall y((X x \& X y \& x \neq y) \rightarrow \tau(\mathrm{R} \mid X) x y)
$$

(10) (4) is true iff every exit is related to every other exit by the (restricted) transitive closure of is-spaced-five-miles-from.

If the meaning of (4) is as it is stated in (10), the sentence will discriminate between (5) and (6) as desired. But, it does so at a price. This talk about the transitive closure of a relation - and this is the authors' point-stands in the way of analyzing the reciprocal as a sequence of two more familiar quantifiers. The shift to a primitive operator does not diminish the reciprocal's ambiguity-one meaning invokes transitive closure and another does not, as (11) still intends every family member to respect every other-

The family members respect each other.

But, we are now invited to think of the reciprocal's meanings as a family of primitive operators corresponding to different sorts of connected graphs for the relations they are applied to. If there is such a family, we should go on to consider, as Dalrymple et al. do, what parameters characterize the meanings that belong to it - that is, why some connected graphs and not others are expressedand what governs their distribution - why, for example, do statives insist on the strongest reciprocity as Fiengo \& Lasnik first observed, and so on. A good outcome on this view is a nice arrangement-maybe even a very nice arrangement - of the reciprocal's several meanings, a bouquet of reciprocals.

Let's try instead to revive the game in (2), namely, that some account of the reciprocal will explain what the two words each and other are doing there. Beyond this, I will try to explain away the reciprocal's several meanings as variation from more familiar causes elsewhere in the sentence, and it happens that the reciprocal needs no structural ambiguity-not even the modest play that (2) gives to the choice of an unspoken determiner for other. But if I intend even less ambiguity than we find in (2), what about Dalrymple et. al.'s argument that there already isn't enough there to express the reciprocal's meaning in (4)?

As I said, it's a good argument, but it's about naïve syntax, where respect each other and are spaced five miles from each other apply the reciprocal to a simple, primitive two-placed relation, $\mathrm{R}$ in (12). What their argument shows, more narrowly, is that each and other with any of their meanings in (2) cannot close off a simple relation and mean what (4) is supposed to mean. They show, in short, that nothing listed in (12) is a fair translation for (4). 


$$
\begin{array}{ll}
X \text { R each other } \Rightarrow & \\
{[\text { Each } \mathrm{x}: \mathrm{Xx}][\forall \mathrm{y}: \mathrm{Xy} \& \mathrm{x} \neq \mathrm{y}]} & \mathrm{R}(\mathrm{x}, \mathrm{y}) \\
{[\text { Each } \mathrm{x}: \mathrm{Xx}][\forall \mathrm{y}: \mathrm{Xy} \& \mathrm{x} \neq \mathrm{y}]\left[\exists \mathrm{Y}^{\prime}: \mathrm{Y}^{\prime} \mathrm{y} \& \forall \mathrm{y}\left(\mathrm{Y}^{\prime} \mathrm{y} \rightarrow \mathrm{Yy}\right)\right]} & \mathrm{R}\left(\mathrm{x}, \mathrm{Y}^{\prime}\right) \\
{[\text { Each } \mathrm{x}: \mathrm{Xx}][\forall \mathrm{y}: \mathrm{Xy} \& \mathrm{x} \neq \mathrm{y}]\left[\exists \mathrm{X}^{\prime}: \mathrm{X}^{\prime} \mathrm{x} \& \forall \mathrm{x}\left(\mathrm{X}^{\prime} \mathrm{x} \rightarrow \mathrm{Xx}\right)\right]} & \mathrm{R}\left(\mathrm{X}^{\prime}, \mathrm{y}\right) \\
{[\text { Each } \mathrm{x}: \mathrm{Xx}][\forall \mathrm{y}: \mathrm{Xy} \& \mathrm{x} \neq \mathrm{y}]\left[\exists \mathrm{X}^{\prime}: \mathrm{X}^{\prime} \mathrm{x} \& \forall \mathrm{x}\left(\mathrm{X}^{\prime} \mathrm{x} \rightarrow \mathrm{Xx}\right)\right]} & \\
{\left[\exists \mathrm{Y}^{\prime}: \mathrm{Y}^{\prime} \mathrm{y} \& \forall \mathrm{y}\left(\mathrm{Y}^{\prime} \mathrm{y} \rightarrow \mathrm{Yy}\right)\right]} & \mathrm{R}\left(\mathrm{X}^{\prime}, \mathrm{Y}^{\prime}\right) \\
{[\text { Each } \mathrm{x}: \mathrm{Xx}][\exists \mathrm{y}: \mathrm{Xy} \& \mathrm{x} \neq \mathrm{y}]} & \mathrm{R}(\mathrm{x}, \mathrm{y}) \\
{[\text { Each } \mathrm{x}: \mathrm{Xx}][\exists \mathrm{y}: \mathrm{Xy} \& \mathrm{x} \neq \mathrm{y}]\left[\exists \mathrm{Y}^{\prime}: \mathrm{Y}^{\prime} \mathrm{y} \& \forall \mathrm{y}\left(\mathrm{Y}^{\prime} \mathrm{y} \rightarrow \mathrm{Yy}\right)\right]} & \mathrm{R}\left(\mathrm{x}, \mathrm{Y}^{\prime}\right) \\
{[\text { Each } \mathrm{x}: \mathrm{Xx}][\exists \mathrm{y}: \mathrm{Xy} \& \mathrm{x} \neq \mathrm{y}]\left[\exists \mathrm{X}^{\prime}: \mathrm{X}^{\prime} \mathrm{x} \& \forall \mathrm{x}\left(\mathrm{X}^{\prime} \mathrm{x} \rightarrow \mathrm{Xx}\right)\right]} & \mathrm{R}\left(\mathrm{X}^{\prime}, \mathrm{y}\right) \\
{[\text { Each } \mathrm{x}: \mathrm{Xx}][\exists \mathrm{y}: \mathrm{Xy} \& \mathrm{x} \neq \mathrm{y}]\left[\exists \mathrm{X}^{\prime}: \mathrm{X}^{\prime} \mathrm{x} \& \forall \mathrm{x}\left(\mathrm{X}^{\prime} \mathrm{x} \rightarrow \mathrm{Xx}\right)\right]} & \\
\quad\left[\exists \mathrm{Y}^{\prime}: \mathrm{Y}^{\prime} \mathrm{y} \& \forall \mathrm{y}\left(\mathrm{Y}^{\prime} \mathrm{y} \rightarrow \mathrm{Yy}\right)\right] & \mathrm{R}\left(\mathrm{X}^{\prime}, \mathrm{Y}^{\prime}\right)
\end{array}
$$

Grant them this argument, but to keep the game in (2) alive, let's deny the naïve syntax of $\mathrm{R}$ and go Davidsonian.

Now (2)'s advocates are eager for each in each other to mean 'each', a distributive quantifier like any other. In a Davidsonian setting, it is given that any distributive quantifier is immediately followed by an event quantifier. That is, to distribute over family members in (13) is just to say that each is the agent in her own event and sounds her note there. Each cannot of course be the agent in the same event. Each family member is rather the agent in her own event, although their several events may be part of a larger, single event, the harmony.

(13) In a perfect four-part harmony, every family member sang a single mournful note. (Taylor 1985, Davies 1991)

$$
\begin{aligned}
& {[\exists e: \operatorname{harmony}(e)][\text { Every } x: \mathrm{M} x]\left[\exists e^{\prime}: e^{\prime} \leq e\right]\left(\operatorname{Agent}\left(e^{\prime} x\right) \& \operatorname{sing}\left(e^{\prime}\right) \&\right.} \\
& \left.[\text { A } y: \mathrm{N} y] \text { Theme }\left(e^{\prime}, y\right)\right) \\
& {[\exists e: \operatorname{harmony}(e)][\text { Every } x: \mathrm{M} x]\left[1 e^{\prime}: e^{\prime} \leq e \& \operatorname{Agent}\left(e^{\prime} x\right)\right]\left(\operatorname{sing}\left(e^{\prime}\right) \&\right.} \\
& \left.[\text { A } y: \mathrm{N} y] \text { Theme }\left(e^{\prime}, y\right)\right)
\end{aligned}
$$

Similar observations govern the interpretation of any distributive quantifier in any syntactic position and commit the Davidsonian to the conclusion that to quantify distributively is to quantify concurrently over events: again, every family member is such that what she did there was a singing of a single mournful note. Here an indefinite description of events would suffice. In Plurals \& Events, some considerations suggested that the event quantifier following every distributive quantifier is in fact a definite description, what she did there, and a plural one at that, as shown in (16), which is to be read 'the events $E$ that there are, if any, where $x$ Is'.

$$
\ldots[\text { Each } x: \Phi(x)][1 E: \forall e(E e \leftrightarrow \Psi(e, x))] \ldots \text { other } \ldots
$$

Now to explain my title and main thesis - if this is one plural, definite description of events and conditional clauses, that is, if-clauses, could very well be another, as we will soon see, then perhaps the event quantifier in (16), the one 
forced by the analysis of distributivity, itself tokens an adverbial construction of some kind. If so, at least some of the apparent variation in the reciprocal's meaning may be passed off as deriving from the vagaries in how we interpret adverbial quantification more generally. To plead the case that the reciprocal is an adverbial construction, I will begin with if-clauses, whose adverbial nature one is not inclined to doubt, highlight some crucial features and then do the same for the reciprocals. The hope is that once you have seen these features at play in the one adverbial construction, your senses will be dulled enough to think that there is another adverbial construction when you see them again.

The title also announces that reciprocals are descriptive. If each other is resolved as two quantifiers, as (2) advocates, they must be something like each of them and other than them or other than that, with tacit pronouns restricting the domains of the quantifiers. Variation in the descriptive content of these pronouns will also be blamed for some of the ambiguity in reciprocal constructions. And, finally, some of it will be attributed to whether the sentence has been taken to assert that some event, in the singular, is such-and-such, or some events, in the plural, are so.

Instead of a bouquet of reciprocals, the many fragrances derive from properties of adverbial modification, the resolution of descriptive anaphora, and the intention to describe one or many events. ${ }^{1}$ None of this is special to reciprocals, which are themselves just the combination of their constituents each and a definite description the others, without any further structural ambiguity.

So, to draw out the common features between conditionals and reciprocity, I should show that the event quantifier that distributivity invokes and the conditional share similar structure, and so - at the very least - that the latter, the conditional, is also a plural, definite description.

\section{Remarks on conditionals}

\subsection{If-clauses as plural, definite descriptions of events ${ }^{2}$}

To this end, consider a puzzle that S.J. Barker (1997) poses concerning the indicated interpretations of (17) and (18):

(17) If a theory is classical, then if it is inconsistent, it is usually trivial. 'Most any a classical inconsistent theory is trivial.'

(18) If a donkey is vaccinated, then if it has a vitamin deficiency, it usually faints.

'Most any a donkey with a vitamin deficiency that is vaccinated faints (then).'

They are the only plausible interpretations for the sentences, but as the paraphrases make plain, they seem to demand that the adverb of quantification be restricted by the coordination of both if-clauses, contrary to the semantic composition prescribed by the syntax. These interpretations escape all the 
accounts that Barker canvasses, which deliver instead the absurd interpretation for (17) shown in (19):

a. $[\forall<e, x>$ : Tx \& classical $(e, x)]\left[\forall e^{\prime}: \operatorname{then}\left(e, e^{\prime}\right) \& \operatorname{inconsistent}\left(e^{\prime}, x\right)\right]$

[Usually $\left.e^{\prime \prime}: \mathrm{R}\left(e^{\prime}, e^{\prime \prime}\right)\right] \operatorname{trivial}\left(e^{\prime \prime}, x\right)$

b. $[\forall e:[\exists x: \mathrm{T} x] \operatorname{classical}(e, x)]$

$\left[\forall e^{\prime}:\right.$ then $\left.\left(e, e^{\prime}\right) \&[\mathrm{w} x: \mathrm{T} x \& \operatorname{classical}(e, x)] \operatorname{inconsistent}\left(e^{\prime}, x\right)\right]$

[Usually $\left.e^{\prime \prime}: \mathrm{R}\left(e^{\prime}, e^{\prime \prime}\right)\right]\left[\mathrm{w} x: \mathrm{T} x \&\right.$ inconsistent $\left.\left(e^{\prime}, x\right)\right] \operatorname{trivial}\left(e^{\prime \prime}, x\right)$

'Any situation in which a theory is classical is such that in any situation where that theory is also inconsistent, it is usually trivial.'

Absurd, because it is suggested that the same theory can be sometimes trivial and sometimes not. I think the downfall of the various accounts Barker considers is the point on which they all agree, namely, that if-clauses are taken to restrict distributive, singular quantifiers, quantifying as in (19) over singular events or over n-tuples of objects and singular events. Barker's puzzle is solved, and the intended interpretations of (17) and (18) are derived compositionally when the ifclauses are taken instead to be plural, definite descriptions of events. Then, we can allow one if-clause simply to restrict the domain of the next event quantifier as shown in (20) and schematically in (21):

$$
\begin{aligned}
& {\left[\mathrm{l} E_{0}: \forall e\left(E_{0} e \leftrightarrow[\exists x: T x] \operatorname{classical}(e, x)\right)\right]} \\
& {\left[1 E_{1}: \forall e\left(E_{1} e \leftrightarrow\left[\exists e_{0}: E_{0} e_{0} \& \operatorname{then}\left(e_{0}, e\right)\right]\left[\mathrm{w}: \mathrm{T} x \& \operatorname{classical}\left(e_{0}, x\right)\right]\right.\right.} \\
& \text { inconsistent }(e, x))]
\end{aligned}
$$

[Usually $\left.e_{2}: E_{1} e_{2}\right]\left[\mathrm{x}: \mathrm{T} x \&\right.$ inconsistent $\left.\left(e_{2}, x\right)\right] \exists e \operatorname{trivial}(e, x)$

'The situations in each of which a theory is classical are such that the situations among them in each of which the theory is inconsistent are such that in most any situation among these, the theory is trivial.'

$$
\left[E_{0}: \Phi\right]\left[1 E_{1}: \ldots E_{0} \ldots \Psi\right]\left[\text { Usually } e_{2}: E_{1} e_{2}\right]\left[u x: \Pi\left(e_{2}, x\right)\right] \Gamma(x)
$$

The first if-clause in (17) denotes all and only events (or situations) in each of which a theory is classical. The second if-clause then narrows the search further-to just the events already among those with a classical theory, in which the theory is also inconsistent. It is then asserted-with the adverb of quantification interpreted in situ where it belongs-that in most of these remaining events, the theory is trivial. If compositionality is to be spared, the meaning of (17) and (18) plainly argues that conditionals are plural, definite descriptions. 


\subsection{As time goes by...}

But, now that conditionals are also found to be plural, definite descriptions, let's mine what is already known about them for what may reflect back on how we understand the reciprocal's definite description of events. There is an important observation that will bear on the analysis of reciprocals, which I will state in a phrase and explain by example. It is that the force of a conditional is understood to be unbounded unless it is bounded as time goes by. When the conditional narrates the flow of time, as in (22), there is scant thought that it comes to imply that the card game goes on forever. The implication absents itself whether or not it is explicitly vacated as in (23):

(22) If a player puts down a card, he puts down another from the same suit on top of it (to complete his play).

(23) If a player first puts down a card, he next puts down another from the same suit on top of it (to complete his play).

(Cf. (Heim 1982) If a gardener buys a sage plant, she buys eight others along with it, where the consequent asserts a symmetric relation among the sage plants.)

The same can be said for (24). He's just three-cannoli Hesh, and Veniero's Pasticceria (342 E 11) needn't worry that his visit will empty their counters. Likewise, it is easy enough to understand that none of (26)-(31) implies an eternal ping-pong game (with ever increasing velocities in the case of (30) and (31)).

(24) If Hesh eats one cannoli, he eats two more (to balance his diet).

(25) If Hesh first eats one cannoli, he then eats two more (to balance his diet).

(26) It is the rare toddler table tennis match where whenever one child hits the ball across the net, the other hits it back.

(27) It is the rare toddler table tennis match where whenever one child first hits the ball across the net, the other hits it back.

(28) If one player hits the ball to the other player, the other player hits the ball to the first player.

(29) If one player hits the ball to the other player, the other player hits it back.

(30) If one player hits the ball fast across the net, the other hits it even faster.

(31) If one player hits the ball fast across the net, the other returns it even faster.

On the other hand, if the conditional flows against time or steps outside it, it becomes that much harder to avoid unbounded consequences. Thus, (32), in contrast to (22), rather implies that it is cards all the way down ad infinitum. The 
implication can be set aside if the context is doped up enough and further conditions made explicit. Still, a robust contrast remains between (22) and (32). As it does between (24) and (34), where Hesh's appetite for cannoli has become insatiable. Similarly, the ping-pong games in (36) and (38) seem to have had no beginning in contrast to their counterparts in (28) and (30).

(32) $\infty$ If a player puts down a card, he has (already) put down another from the same suit under it (during that play).

(33) If a player puts down a card last, he has (already) put down another from the same suit under it (during that play).

(34) $\infty$ If Hesh eats one cannoli, he has (already) eaten two before (to balance his diet).

(35) If Hesh eats one cannoli for his last bite, he has (already) eaten two before (to balance his diet).

(36) $\infty$ If one player hits the ball to the other player, the other player has hit the ball to the first player.

(37) If one player hits the ball back to the other player, the other player has hit the ball first.

(38) $\infty$ If one player hits the ball fast across the net, the other has hit it even faster.

(39) If one player returns the ball fast across the net, the other has hit it even faster.

(40) If one player returns the ball fast across the net, the other has served it even faster.

How then do we represent this interplay between time's arrow and the force of the conditional?

Recall first that conditionals have a fixed temporal orientation, as Geis (1973) and McCawley (1981) point out. One might have thought prior to considering temporal orientation that the equivalence between the sentences in (41) is just an instance of the equivalence between only and the universal quantifier, seen in (43) applying to quantification over events.

(41) If a set has only finitely many subsets, it is finite. (McCawley 1981: 49ff.) Only if a set is finite does it have only finitely many subsets.

(42) If butter is heated, it melts. (McCawley 1981: 49ff.)

Only if butter melts is it heated.

$[\forall e:$ if $\Phi] \Psi \leftrightarrow[$ Only $e:$ if $\Psi] \Phi$

$*[\forall e:$ if $\Phi]\left[\exists e^{\prime}: e \leq e^{\prime}\right] \Psi \leftrightarrow[$ Only $e$ : if $\Psi]\left[\exists e e^{\prime}: e \leq e^{\prime}\right] \Phi$ 
But, as Geis and McCawley say, the equivalence breaks down in (42) in the presence of the temporal relation. No matter the adverb of quantification, any temporal relation orients itself from the if-clause to the matrix clause. Thus swapping the clauses in (42) is not truth-preserving as it changes the temporal relations between them, as shown in (44). Now fixing the temporal orientation in (24), say, guarantees by itself only that Hesh eats two cannoli after he eats one, without explaining yet how we grasp that he stops at three. What will excuse Hesh from the dessert tray?

\section{2. ... and other things remaining equal}

Conditionals stand as qualified judgments, no matter how confident or reliably they are asserted. George Bailey, the pillar of his community of Bedford Falls, a cheerful, law-abiding, model citizen, kind and generous with his fellow creatures, a man of well-kept habits and good grooming knows that he should dress before breakfast if he wakes up early enough, and therefore (45) very aptly describes George. Despite the generality of what (45) asserts, it however implies no flaw in George's character if he should wake up with a fever and order breakfast in bed. The conditional (45) does not imply (46), although on the face of it, it should, since waking up early and feverish is still an instance of waking up early all the same. The examples (47)-(49) are further instances of this well-known problem of antecedent strengthening.

(45) If George Bailey wakes up early, he dresses before breakfast.

(46) If George Bailey wakes up early and he is wracked by fever, he dresses before breakfast.

If this match were struck, it would light.

(Stalnaker 1968)

If this match had been soaked in water overnight and it were struck, it would light.

(48) If he has told a lie, he must go to confession.

(Heim 1984)

If he has told a lie and shot himself right after, he must go to confession.

If Smedley finishes his book, I'll be happy. $\quad$ (Lycan 1991)

If Smedley finishes his book and concludes it with a vicious and totally unfair personal attack on me, I'll be happy.

As every speaker grasps, conditionals are offered up against a presumed background of other conditionals, causal laws, shared beliefs and so on. What (45) warrants is only the qualified judgment that all other things being equal, whenever George Bailey wakes up early, he dresses before breakfast. And, of course, if feverish or dead, all other things are very much not equal, and (45), so understood, does not entail (46). 
We might now wonder where in the course of understanding a conditional do we make this concession to prevailing conditions. Is the thought as in (50) or as in $(51)$ or $(52)$ ?

(50) All other things being equal, if George Bailey wakes up early, he dresses before breakfast.

(51) If George Bailey wakes up early and all other things being equal, he dresses before breakfast.

(52) If George Bailey wakes up early; all other things being equal, he dresses before breakfast.

Adopting a crucial insight and proposal from C. Barker (1993: 13ff.,1996: 254ff.), I think the existence of so-called weak and strong conditionals reveals that the qualifying condition is felt somewhere in the neighborhood shown in (52). Recall the import of the weak conditional in (53). As civic-minded, law-abiding and virtuous as George Bailey is, (53) does not imply that he will empty his pocket of quarters, but only that some of them will be put in the parking meter, presumably as the parking regulations require. The conditional is said to be weak in that it commits some but not all of his quarters to the meter.

(53) If George Bailey has a quarter in his pocket, he will put it in the parking meter. (Schubert \& Pelletier 1989)

(54) If George Bailey has a quarter in his pocket at Christmas, he hands it over to Santa Claus.

On the other hand, the Christmas season and George's own love of humanity fleece him every time, and according to the strong conditional in (54), George turns his pockets inside out, giving every quarter he has to Santa's collection.

The weak conditional suggests that with each quarter, the prevailing conditions are reassessed, as in the logical form in (55), where I use 'ceteris-paribus( $e, e$ ")' for 'all other things being equal at $e$ " to how they are at $e .{ }^{, 3}$

$$
\begin{aligned}
& {[\mathrm{l} E: \forall e(E e \leftrightarrow[\operatorname{An} x: \mathrm{Q} x] \mathrm{H}(e, \mathrm{~b}, x))][\forall e: E e]} \\
& {\left[\exists E^{\prime}: \exists e^{\prime} E^{\prime} e^{\prime} \& \forall e^{\prime}\left(E^{\prime} e^{\prime} \rightarrow \mathrm{Will}\left(e, e^{\prime}\right)\right)\right]} \\
& {\left[\mathrm{l} E \text { " : } \forall e^{\prime \prime}\left(E^{\prime \prime} e " \leftrightarrow E^{\prime} e^{\prime \prime} \& \text { ceteris-paribus }(e, e ")\right)\right]\left[\forall e ": E^{\prime \prime} e^{\prime \prime}\right]} \\
& {\left[\mathrm{w}: \mathrm{Q} x \& \mathrm{H}\left(e^{\prime \prime}, \mathrm{b}, x\right)\right]\left[\text { the } y: \mathrm{M}\left(y, e^{\prime \prime}\right)\right] \mathrm{P}(e,, \mathrm{~b}, x, y)}
\end{aligned}
$$

'Whenever George Bailey has a quarter in his pocket, thereupon will be some event(s) at which, if all things are still equal then, he puts it in the parking meter.' 


$$
\begin{aligned}
& {[\mathrm{l} E: \forall e(E e \leftrightarrow[\operatorname{An} x: \mathrm{Q} x] \mathrm{H}(e, \mathrm{~b}, x))][\forall e: E e]} \\
& {\left[\exists E^{\prime}: \exists e^{\prime} E^{\prime} e^{\prime} \& \forall e^{\prime}\left(E^{\prime} e^{\prime} \rightarrow \text { Will }\left(e, e^{\prime}\right)\right)\right]} \\
& {\left[1 E^{\prime \prime}: \forall e^{\prime \prime}\left(E^{\prime \prime} e^{\prime \prime} \leftrightarrow E^{\prime} e^{\prime \prime} \& \text { ceteris-paribus }\left(e, e^{\prime \prime}\right)\right)\right]\left[\forall e^{\prime \prime}: E^{\prime \prime} e^{\prime \prime}\right]} \\
& {\left[\mathrm{w}: \mathrm{Q} x \& \mathrm{H}\left(e^{\prime \prime}, \mathrm{b}, x\right)\right] \mathrm{G}\left(e^{\prime \prime}, \mathrm{b}, x, \mathrm{~s}\right)}
\end{aligned}
$$

'Whenever George Bailey has a quarter in his pocket at Christmas, thereupon will be some event(s) at which, if all things are still equal then, he hands it over to Santa Claus.'

With any quarter, if the prevailing conditions have changed, so might George's behavior. Suppose then that George faces a parking meter with a pocketful of quarters. According to (55) - and it suffices to consider the paraphrase-each quarter in his pocket must meet the condition that either it goes into the parking meter or there is a moment when, non ceteris paribus, all things are not equal. That moment comes of course when the parking meter is not still hungry, after which the quarters can stay in his pocket. Notice-a formal point - it is crucial to this account that the ceteris paribus condition apply to $e$ ", the events that the consequent clause describes. The events described by the antecedent clause, the states of having a quarter in his pocket are all contemporaneous. So, all other things being equal holds of one of these states only if it holds of them all.

The weak conditional is about parking meters, which are one thing. World hunger is quite another, which George Bailey's quarters will never alleviate. In the strong conditional in (54), the hearer has no reason to believe that the ceteris paribus condition is affected by the events described and so understands that the background conditions at the moment of utterance persist throughout. With each quarter, the world is still hungry, and so George Bailey feeling its pain at Christmas time hands over every quarter he has. Locating the ceteris paribus condition as shown in (55) and (56) shows there to be no formal ambiguity between weak and strong conditionals as Barker $(1993,1996)$ says. That ceteris paribus conditions intrude on conditional thoughts is just a pragmatic fact of life. They are pervasive, as (45)-(49) attest, and it must be that they intrude somewhere. So why not here? A retreat to structural ambiguity to discriminate between strong and weak conditionals neglects altogether that such conditionals are understood ceteris paribus. (See Garrett (1998) for further arguments structural ambiguity.)

Now, the conclusion that the ceteris paribus condition holds of the events described by the consequent clause and the earlier observation that a fixed temporal relation intervenes recommend that we gloss the condition not as all other things being equal but rather as all other things remaining equal. Illustrating in one example the effects seen so far, the conditional in (57) is both weak in that it does not imply that the player moves all the pieces he has on black squares and bounded in that it does not imply that his turn never ends.

If a player has a piece on a black square, he moves it to a black square. 


$$
\begin{aligned}
& {[\mathrm{l} E: \forall e(E e \leftrightarrow[\mathrm{A} x: \mathrm{P} x][\mathrm{A} y: \mathrm{M} y] \mathrm{H}(e, x, y))][\forall e: E e]} \\
& {\left[\exists E,: \exists e ' E^{\prime} e^{\prime} \& \forall e^{\prime}\left(E^{\prime} e^{\prime} \rightarrow \mathrm{Will}\left(e, e^{\prime}\right)\right)\right]} \\
& {\left[1 E^{\prime \prime}: \forall e^{\prime \prime}\left(E^{\prime \prime} e^{\prime \prime} \leftrightarrow E^{\prime} e^{\prime \prime} \& \text { ceteris-paribus }\left(e, e^{\prime \prime}\right)\right)\right]\left[\forall e^{\prime \prime}: E^{\prime \prime} e^{\prime \prime}\right]} \\
& \text { he moves it to a black square(e") }
\end{aligned}
$$

'Whenever a player has a piece on a black square, thereupon will be some event(s) at which, if all things are still equal then, he moves it to a black square'

The ceteris paribus condition as it is understood in this case means something like 'it remaining that the player has not moved yet'. As before, if the player moves one piece, the condition on every other piece is satisfied, there is an event at which it is no longer the case that the player has not moved yet. Hence, the conditional is weak. With a little more precision, the boundedness follows as well. The condition ceteris-paribus(e,e") should be understood as 'it remaining at $e$ " that the player has not moved yet in $e$ 's turn'. So suppose that the player in his turn first moves a piece to position Q2. There is then the new state $e$ of having a piece on a black square, Q2. The conditional requires that there follow an event $e$ " where if the player has not yet moved in $e$ 's turn, he moves again. But, the movement to Q2 was itself the movement in $e$ 's turn and so no further movement is implied, as desired.

A similar understanding of the ceteris paribus condition excuses Hesh from the desert tray in (24). Here it's that it remains at $e$ " that Hesh has not already had a second helping at $e$ 's seating. If, on the other hand, the speaker does not grasp the sense in which all other things would not remain equal, she does not doubt that they remain so and the conditional is both strong and unbounded, as happens to poor Hesh in (34), reasoning as in (59):

'Whenever Hesh eats one cannoli, thereupon will be some event(s) at which, if all things are still equal then, he has already eaten two before.'

In sum, for weak and strong conditionals and for bounded and unbounded conditionals alike, there is but one canonical logical form, the schema for which is in (60):

$$
\begin{aligned}
& \text { If } \Phi, \Psi \Rightarrow \\
& {[\mathfrak{l} E: \forall e(E e \leftrightarrow \Phi)][\forall e: E e]\left[\exists E^{\prime}: \exists e^{\prime} E^{\prime} e^{\prime} \& \forall e^{\prime}\left(E^{\prime} e^{\prime} \rightarrow e \leq e^{\prime}\right)\right]} \\
& {\left[\mathrm{l} E^{\prime \prime}: \forall e^{\prime \prime}\left(E^{\prime \prime} e^{\prime \prime} \leftrightarrow E^{\prime} e^{\prime \prime} \& \text { ceteris-paribus }\left(e, e^{\prime \prime}\right)\right)\right]\left[\forall e^{\prime \prime}: E^{\prime} e^{\prime \prime}\right] \Psi}
\end{aligned}
$$

'Whenever $\Phi$, thereupon will be some event(s) at which, if all other things remain equal, $\Psi$.'

The if-clause is itself a plural, definite description of events, the temporal relation is fixed so that the ceteris paribus condition on the consequent event amounts to 
all other things remaining equal, as I said. The universal quantifiers will render all conditionals strong and unbounded except to the extent the hearer clearly grasps a ceteris paribus condition that manages to weaken or bound the conditional as time goes by. Again, in brief, the conditional is a plural, definite description of events that modifies via a temporally-oriented ceteris paribus condition. ${ }^{4}$ Now let's see in what respect reciprocals conceal adverbials resembling conditionals.

\section{The reciprocal adverbial}

Discussing the examples (61)-(70) in (1978) "The Logic of Reciprocity",

(61) The plates are stacked on top of one another.

(62) The plates are stacked underneath one another.

(63) The boxes are nested inside one another.

The boxes are placed outside one another.

(64) The children are lined up behind one another.

(65) The children are lined up in front of one another.

(66) The guests followed one another (into the room).

(67) The guests preceded one another (into the room).

(68) The children are lined up to the right/left of one another.

(69) They are fathers of one another./ They are one another's fathers. The numbers from one to four succeed one another.

(70) The monarchs of England succeeded one another (to the throne).

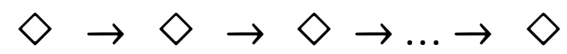

Langendoen points out that their use contrasts in situations of the type (71). He remarks that (69) for most speakers implies a contradiction, unlike the truism that (70) asserts, and goes on to say that:

"It would appear that the ordering of elements that is required in order for such sentences to be so used is, however, a natural (or possibly culturally determined) one. We normally stack things one on top of the other rather than the other way around, line up one behind the other rather than one in front of the other, and view time as progressing from earlier to later rather than from later to earlier. Whether we are more likely to put nested boxes one inside the other or the other way around, I cannot say, but we generally perceive them to be nested one inside the other rather than the 
other way around. Finally, since there is no general preference for arranging things from left to right as opposed to arranging them from right to left, either ordering is acceptable as a basis for the use of sentences like $[(68)]$ in situations of the type [(71)]." (193).

In other words, reciprocity is unbounded unless bounded as time goes by. Note that (62) can fit in just fine as an instance of (71) if we imagine that magnetic plates have been placed underneath a shelf, each attracted to the plate above it.

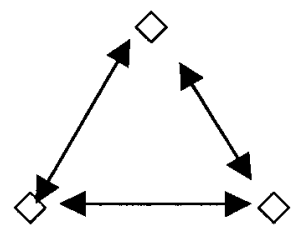

The intrusion of time's arrow on judgments about reciprocity is quite surprising if the decision is thought of as a search among connected graphs. Whether it's (71) or (72), why should the reciprocal apply different graphs to one relation $x$ is stacked on top of $y$ and its inverse $x$ is stacked beneath $y$, according to which fits time's arrow?

It is less surprising that the adverbial clauses in (75) and (76) fix the manner in which they modify the matrix clause, prescribing in particular the temporal relation between them. The point of these clauses is to give a point-wise characterization of the ensemble events, the finished stack, where what happens to each plate is described in terms of the prevailing conditions at the moment it happens to the plate. In this stacking of plates, each plate not yet stacked is to be stacked on the plates already stacked.

(73) The plates are stacked on top of each other.

(74) The plates are stacked each on top of the others.

(75) The plates are stacked, each stacking on top of the others.

(76) The plates are stacked, each (to be stacked) stacking on the stacked.

(77) $\exists E[$ the $X: \operatorname{plates}[X]](\operatorname{stack}[E] \&$ Theme $[E, X] \&$

$[\mathrm{l} X:$ Theme $[E, X]][$ Each $x: X x]\left[\mathrm{l} E^{\prime}:\right.$ Overlaps $\left[E^{\prime}, E\right] \&$ Theme $\left.\left[E^{\prime}, x\right]\right]$

$\left[\exists E^{\prime}: \mathrm{t}\left(E^{\prime \prime}\right) \leq \mathrm{t}\left(E^{\prime}\right)\right]\left[\mathrm{l} Y:\right.$ Others $[x, Y] \&$ Theme $\left.\left[E^{\prime \prime}, Y\right]\right]$ on-top-of $\left.\left[E^{\prime \prime}, x, Y\right]\right)$

'The plates stack,

(with) them each stacking

on top of the others stacked.'

Even the bottom plate is stacked on whatever plates there are if any that have already been stacked. The second-order, definite description, the others (better glossed as 'whatever others if any') should not itself be taken to assert the existence of those it describes." 
If there is no unfolding event and evolution of prevailing conditions, reference to those in place at one moment coincides with reference to those in place at any other, from which the fundamental contrast between stative and eventive reciprocity follows. So, to paraphrase, (1) should be read as in (78):

(78) 'The family members respected themselves, each respecting the others respected; and they paid their respects, each paying it at the funerals of the others who paid it.'

The reference to the moment at which the individual point enters the event also repairs the freeway problem in (4), which should be paraphrased as in (79):

'The freeway exits are spaced, each being spaced five miles from the others (already) spaced.'

This closes the gap in situation (5), in that as one drives north on the Palisades Parkway, Exit 8 is not five miles from the exits that have come before it. In order to compel strong reciprocity for the stative in (1) and to repair (4), it must be, as Dalrymple et al. op. cit. hold, that the reciprocal refers unambiguously to the others and never to some others (as (2) would allow). But, it is the others in a situation local to the individual whose circumstances are being described. Weaker conditions for reciprocity will then creep in-and only then-when the local conditions vary as time goes by. The formal point-looking now at the logical form in (77) - is that, in describing the others, the crucial reference to local conditions can only be achieved if each is followed by that description of events $E$ ' at which the individual $x$ moves alone. ${ }^{6}$

Not just stative $v s$. eventive matters, but temporal orientation too. That is, the difference between (61) and (62), and between Langendoen's truism in (80) and (82).

(80) The monarchs of England succeeded each other (to the throne).

(81) The monarchs of England succeeded, each succeeding the others who succeeded.

(82) \#The heirs to the Rockefeller estates bequeathed their fortunes to each other.

(83) \#The heirs to the Rockefeller estates bequeathed their fortunes, each bequeathing to the others who bequeathed.

It confounds (82) that a bequeather is said to bequeath to former bequeathers even deader than he is.

Besides the temporal orientation on display here, reference to the others in the local conditions accommodates more fine-grained discriminations, when we reflect on what might be meant by local conditions. It seems to be another truism that once an English monarch-always an English monarch. Less so, the condition of being a successor, which is tied more closely to the circumstances of 
succession. This appears to be the basis for the contrast between (80) and (84). A successor succeeds a reigning monarch rather than another successor.

\#The successors to the English throne succeeded each other (bloodlessly).

A contrast between (80) and (84) emerges in logical form, if we think of others as anaphoric in content so that in (80) it denotes other monarchs in the local circumstances and in (84), other successors:

$\exists E[$ the $X: \operatorname{monarchs}[E, X]](\operatorname{Agent}[E, X] \& \operatorname{succeed}[E] \&$ $[$ Each $x: X x]\left[1 E^{\prime}:\right.$ Overlaps $\left[E^{\prime}, E\right] \&$ Agent $\left.\left[E^{\prime}, x\right]\right]\left[\exists E^{\prime}: \mathrm{t}\left(E^{\prime \prime}\right) \leq \mathrm{t}\left(E^{\prime}\right)\right]$ $\left[\imath Y\right.$ : Others $[x, Y] \&$ monarchs $\left[E^{\prime \prime}, Y\right] \&$ Agent $\left.\left[E^{\prime \prime}, Y\right]\right]$ Theme $\left.\left[E^{\prime}, Y\right]\right)$

'The monarchs of England succeeded, (with) them each succeeding at some point the monarch(s) at that time who had succeeded to the throne.'

$$
\begin{aligned}
& \text { \# } \exists E[\text { the } X: \text { successors }[E, X]](\text { Agent }[E, X] \& \text { succeed }[E] \& \\
& {[\text { Each } x: X x]\left[1 E^{\prime}: \text { Overlaps }\left[E^{\prime}, E\right] \& \text { Agent }\left[E^{\prime}, x\right]\right]\left[\exists E^{\prime \prime}: \mathrm{t}\left(E^{\prime \prime}\right) \leq \mathrm{t}\left(E^{\prime}\right)\right]} \\
& \left.\left[\mathrm{l} Y: \text { Others }[x, Y] \& \text { successors }\left[E^{\prime \prime}, Y\right] \& \text { Agent }\left[E^{\prime \prime}, Y\right]\right] \text { Theme }\left[E^{\prime}, Y\right]\right) \\
& \text { \#'The successors to the English throne succeeded, } \\
& \text { (with) them each succeeding at some point } \\
& \text { the successor(s) at that time who had succeeded to the throne.' }
\end{aligned}
$$

What is peculiar about (86) and likewise (84) is that there is no successor in the circumstances surrounding a succession except for he himself who is about to succeed. I think a less orderly succession makes the point even clearer. Suppose each succession occurs against a field of contenders or candidates and that no prince is ever a contender at more than a single succession, win or lose. Although the monarchs have all been contenders, the sentences in (87) are odd because none is a contender against his successor prior to his successor's succession. No English monarch ever contended against any other English monarch.

\#The contenders for the English throne succeeded each other (bloodlessly).

\#The candidates for the English throne succeeded each other (bloodlessly).

The contrast under discussion rests on more than a gross difference between a rather individual-level predicate like monarch and a stagier-level predicate like successor or contender. The monarch can be described more episodically if it fits the occasion, as it does in (88), where the monarch is still the tenant of the throne up to the moment he is succeeded.

(88) The tenants of the English throne succeeded each other (bloodlessly). The occupants of the English throne succeeded each other (bloodlessly). 
The contrast between (87) and (88) is a striking fact about weak reciprocity and about what it takes for a context to make it intelligible. How could it tell apart monarchs, tenants and occupants from successors, candidates and contenders except by reference to the others as they are at the moment of the individual succession?

\subsection{Subatomic reciprocal clauses}

In treating the reciprocal construction as adverbial, my point so far has been to recognize a pattern of event quantifiers and to consider what follows from the fixed temporal relations among the events described. In this respect, it has been fair to treat (73)-(76) as like paraphrases despite their differences in the size and content of the adverbial clauses. In the general case, however, the sense of a reciprocal construction may be lost in a paraphrase that puts the verb within the scope of each. Thus (89) is not paraphrased by any of the candidates (90)-(93). ${ }^{7}$

(89) The sharks ate each other up.

(90) The sharks each ate the others up.

(91) The sharks each ate some of the others up.

(92) The sharks ate, each eating the others up.

(93) The sharks ate, each eating some of the others up.

We can imagine a cartoon animation for (89) in which the sharks are caught in a circular feeding frenzy that leaves behind nothing but their skeletal remains adrift. Such a scene makes (89) true, but none of (90)-(93) describes it. In the same vein, notice that (94)-(98) could all be true even where only the entire group sits at the cusp of catastrophe.

(94) The zebra mussels are choking each other in the drainpipe.

(95) The bamboo shoots smother each other.

(96) The politicians stifle each other.

(97) The motors overheated each other.

(98) The cockroaches suffocated each other.

That is, if there had been only one less cockroach, they would have all made it. The sentence (98) is true under the circumstances that there has been just one too many, but none of the purported paraphrases in (99) would be.

(99) The cockroaches each suffocated the others.

The cockroaches each suffocated some of the others.

The cockroaches suffocated, each suffocating the others.

The cockroaches suffocated, each suffocating some of the others. 
The same observation distinguishes the remaining sentences from their corresponding paraphrases. All the paraphrases stumble in assigning each a scope that includes the verb. Of course, this is unavoidable if the verb is a primitive relation, $x$ suffocates $y($ at $e$ ). But, Davidsonian decomposition enables us to draw the essential distinction. In (100), the logical form for (98) does not assert that what the individual cockroach did was a suffocation on its own:

$$
\begin{aligned}
& \exists E \text { the } X: \text { cockroaches }[X]](\text { Agent }[E, X] \& \text { suffocate }[E] \& \text { Theme }[E, X] \& \\
& {[1 X: \text { Agent }[E, X]][\text { Each } x: X x]\left[\mathrm{l} E^{\prime}: \text { Overlaps }\left[E^{\prime}, E\right] \& \text { Agent }\left[E^{\prime}, x\right]\right]} \\
& \left.\left[\exists E^{\prime}: \mathrm{t}\left(E^{\prime}\right) \leq \mathrm{t}\left(E^{\prime}\right)\right]\left[\mathrm{\imath} Y: \text { Others }[x, Y] \& \text { Agent }\left[E^{\prime}, Y\right]\right] \text { Theme }\left[E^{\prime}, Y\right]\right)
\end{aligned}
$$

'The cockroaches suffocate themselves, (with) them each acting against the others that acted.'

It only requires that each cockroach acted on the others in some way that contributed to their mass suffocation. In contrast the logical form for the likes of (99) does of course engage each cockroach in an individual act of suffocation, making it false in the imagined context:

(101) $\exists E$ [the $X$ : cockroaches $[X]]$ (Agent $[E, X] \&$ suffocate $[E] \&$ Theme $[E, X] \&$ $[\mathrm{u} X$ : Agent $[E, X]][$ Each $x: X x]\left[\mathfrak{\imath} E^{\prime}:\right.$ Overlaps $\left[E^{\prime}, E\right] \&$ Agent $\left.\left[E^{\prime}, x\right]\right]$ (suffocate $[E] \&\left[\exists E^{\prime \prime}: \mathrm{t}\left(E^{\prime \prime}\right) \leq \mathrm{t}\left(E^{\prime}\right)\right]\left[1 Y:\right.$ Others $[x, Y] \&$ Agent $\left.\left[E^{\prime \prime}, Y\right]\right]$ Theme $\left.\left[E^{\prime}, Y\right]\right)$ )

'The cockroaches suffocate themselves, (with) them each suffocating the others that were also agents.'

Thus, the way in which (89) and (94)-(98) are ordinarily understood lends support to the view that the reciprocal construction presents an adverbial clause with its own internal event quantification, and it is an adverbial clause on a subatomic scale that only a Davidsonian can see.

This view of the reciprocal construction also suggests a way to sketch out an answer to the following puzzle. Out on the avenue in 1982, Lauri Carlson saw a scaffold against some windows bearing two window-washers, of whom he reports truthfully that:

(102) The window-washers hoisted themselves up.

(103) The window-washers hoisted each other up.

As it turns out, the weak collective interpretation of (102) and the weak reciprocity of (103) are equally good reports of what happened. With a naïve syntax in mind, one might expect that the reciprocal would always entail the 
collective reflexive, in that the meaning of (103) could only be that the windowwashers hoisted themselves up in an each-otherly way:

(104) Hoist $(E, X, X)$, 'X hoist themselves up'. Each-otherHoist $(E, X) \rightarrow$ $\operatorname{Hoist}(E, X, X)$

And so, it is a puzzle that such entailments should ever fail as they do in (105)(110):

(105) The pitchers sat alongside each other.

(106) *The pitchers sat alongside themselves.

(107) The blood platelets surrounded each other.

(108) *The blood platelets surrounded themselves.

(109) The magnets repelled each other.

(110) ${ }^{*}$ The magnets repelled themselves. ${ }^{8}$

Towards an account of this contrast, let's suppose (as I argued in Plurals $\&$ Events and in more recent work) that the constituents of a sentence are always about the same events unless distributive quantifiers (or adverbs) introduce other events. Thus, the reflexives in (106), (108) and (110) refer to participants participating in the same events as their subjects are said to participate in, as in the logical forms (111)-(113), where all participate in the events $E$ :

(111) $\exists E[$ the $X: \operatorname{pitchers}[X]]($ Theme $[E, X] \& \operatorname{sit}[E] \&$ [ $1 X: \operatorname{selves}[X]]$ alongside $[E, X])$

(112) $\exists E[$ the $X$ : platelets $[X]]($ Theme $[E, X] \&$ surround $[E] \&$ [l $X: \operatorname{selves}[X]]$ Location $[E, X])$

(113) $\exists E$ [the $X$ : magnets $[X]](\operatorname{Agent}[E, X] \& \operatorname{repel}[E] \&$ $[\mathrm{l} X: \operatorname{selves}[X]]$ Theme $[E, X])$

The point of these predicates is that they impose a particular topology on their participants. Where the participants participate in the very same events, those events should fit a scene that arranges the subject participants opposite the object participants, which is of course impossible when the subject participants are the object participants, and hence the reflexives are all anomalous.

In contrast, the reciprocal construction, as it includes the distributive quantifier each, introduces other events. So consider the logical form for (105):

(114) $\exists E[$ the $X: \operatorname{pitchers}[X]]$ (Theme $[E, X] \& \operatorname{sit}[E] \&$

$[\mathrm{l} X:$ Theme $[E, X]][$ Each $x: X x]\left[\mathfrak{\imath} E^{\prime}:\right.$ Overlaps $\left[E^{\prime}, E\right] \&$ Theme $\left.\left[E^{\prime}, x\right]\right]$

$\left[\exists E^{\prime \prime}: \mathrm{t}\left(E^{\prime \prime}\right) \leq \mathrm{t}\left(E^{\prime}\right)\right]\left[1 Y:\right.$ Others $[x, Y] \&$ Theme $\left.\left[E^{\prime \prime}, Y\right]\right]$ alongside $\left.\left[E^{\prime}, Y\right]\right)$

'The pitchers sit, each (sitting) alongside the pitchers seated.' 
In (114), the pitchers sit, and each of them is in his own event that puts him in the right topological relation alongside the other pitchers. Again, I think the only way out from this puzzle turns to the event quantification within the reciprocal construction in order to explain away those cases where the reciprocal fails to entail the collective reflexive.

\section{The descriptive content of reciprocal pronouns}

So far, I have canvassed the weakening in reciprocity induced by the temporal relations implicit in adverbial modification, the arrangement of event quantifiers, and the subatomic content of some adverbial clauses. A weak reciprocity can also come about simply by varying who are taken to be the parties to a reciprocal relation. Examples like the following are well-known. To mistrust each other is a stative and therefore strong reciprocal. Nevertheless the interpretation of (115) that says that every New Yorker mistrusts every other New Yorker can give way to a gentler reading that implies only that Eastsiders mistrust Westsiders and Westsiders mistrust Eastsiders. Similarly, the remaining sentences in (116)-(121) need only be concerned with cross-town rivalries.

(115) Eastsiders and Westsiders mistrust each other.

(116) The Eastsiders and the Westsiders mistrust each other.

(117) Some Eastsiders and some Westsiders mistrust each other.

(118) No Eastsiders and no Westsiders mistrust each other.

(119) Few Eastsiders and Few Westsiders mistrust each other.

(120) Some Eastsiders and no Westsiders mistrust each other.

(121) Exactly twenty Eastsiders and no more than fifty Westsiders mistrust each other.

And, as in (118)-(121), it isn't necessary that the sentence contain DPs that refer directly to the cross-town rivals in order for the reciprocity to be restricted to them. As with the earlier conditions for weakening reciprocity, the effects seen here are not limited to the reciprocal construction either. In (122)-(124), the rivalry is understood in the same terms, and however that is to be expressed, we must settle on some referent for one and some other referent for the others, as these are obviously separate DPs making their own contribution to the meaning of the sentence:

(122) Eastsiders chafed. Westsiders seethed. One insulted the other, each lobbing barbs at the other's privates.

(123) The Eastsiders chafed. The Westsiders seethed. One insulted the other, each lobbing barbs at the other's privates.

(124) Few Eastsiders chafed. Few Westsiders seethed. One refrained from insulting the other, neither lobbing barbs at the other's privates. 
The DPs one and the other are obviously anaphoric, and for the reasons that Evans $(1977,1980)$ lays out, (124) and also (125) show that they are descriptive anaphors. ${ }^{9}$

(125) (Some) Eastsiders were heard to have chafed somewhere, and (some) Eastsiders were (also) seen to have chafed nearby. One was suspected of intending harm to the other until it was discovered that the one was the other.

As before, my point will be that the vagaries of interpreting reciprocal constructions derive from more familiar features found elsewhere. From what has been said so far the logical form for (115)-(121) could only be something along the lines of (126) or (127), whatever the content of one or them turns out to be. ${ }^{10}$

$\exists E$ (Eastsiders and Westsiders mistrust $[E] \&$ $[\mathrm{l} X:$ One $[X]][$ Each $x: X x]\left[\mathrm{l} E^{\prime}:\right.$ Overlaps $\left[E^{\prime}, E\right] \&$ Experiencer $\left.\left[E^{\prime}, x\right]\right]$ $\left[\exists E^{\prime \prime}: \mathrm{t}\left(E^{\prime \prime}\right) \leq \mathrm{t}\left(E^{\prime}\right)\right]\left[1 Y:\right.$ Others $[x] \&$ Experiencer $\left.\left[E^{\prime \prime}, Y\right]\right]$ Theme $\left.\left[E^{\prime}, Y\right]\right)$

'Eastsiders and Westsiders mistrust, each of one (mistrusting) the other.'

(127) $\exists E$ (Eastsiders and Westsiders mistrust $[E] \&$

$[\mathrm{l} X:$ Them $[X]][$ Each $x: X x]\left[1 E^{\prime}:\right.$ Overlaps $\left[E^{\prime}, E\right] \&$ Experiencer $\left.\left[E^{\prime}, x\right]\right]$ $\left[\exists E^{\prime \prime}: \mathrm{t}\left(E^{\prime \prime}\right) \leq \mathrm{t}\left(E^{\prime}\right)\right]\left[\mathrm{l} Y:\right.$ Others $[x] \&$ Experiencer $\left.\left[E^{\prime \prime}, Y\right]\right]$ Theme $\left.\left[E^{\prime}, Y\right]\right)$

'Eastsiders and Westsiders mistrust, each of them (mistrusting) the other.'

These pronouns bear a two-fold burden in serving the description of a cross-town rivalry between Eastsiders and Westsiders: i. No New Yorker should be compelled by the assertion of (115) to mistrust anyone inside his own neighborhood, and ii. it must be conveyed that the rivalry between neighborhoods is reciprocated, Eastsiders against Westsiders and Westsiders against Eastsiders.

Throughout, I have resolved each other as something roughly put as in (128), where I mention 'there' to flag reference to events.

Each other $\Rightarrow$ Each of them there... the others among them there

(128) neglects to say other than who, and of course if strong reciprocity is meant, it has to be other than $x$ for each $x$ among them as in (129):

(129) Each other $\Rightarrow$ [Each $x$ : of them there $].$. those among them there other than $x$

But, if something other than strong reciprocity is intended, it could just as well be 'other than them' for some appropriately chosen 'them' rather than 'other than $x$ '. Suppose that in representing (115) according to (126) or (127), I have already contrived that one in (126) or them in (127) denotes the Eastsiders. In a cross- 
town rivalry, an Eastsider mistrusts not just anyone in town other than himself. He rather mistrusts those in town other than the Eastsiders, which is to say, the Westsiders. That is, if the restriction on each is somehow understood to be the Eastsiders, the reference of them in other than them should be the same:

(130) Each other $\Rightarrow$ [Each $x$ : of the Eastsiders there]... those among them there other than the Eastsiders
$\exists E$ (Eastsiders and Westsiders mistrust $[E] \&$
$[\mathrm{u} X:$ Eastsiders $[E, X]][$ Each $x: X x]$
$\left[\mathrm{l} E^{\prime}:\right.$ Overlaps $\left[E^{\prime}, E\right] \&$ Experiencer $\left.\left[E^{\prime}, x\right]\right]\left[\exists E^{\prime}: \mathrm{t}\left(E^{\prime \prime}\right) \leq \mathrm{t}\left(E^{\prime}\right)\right]$
[l$Y: Y$ other than $X \&$ Experiencer $\left.\left[E^{\prime \prime}, Y\right]\right]$ Theme $\left.\left[E^{\prime}, Y\right]\right)$
'Eastsiders and Westsiders mistrust, each of the Eastsiders there (mistrusting) those there other than Eastsiders.'

The proposal is that the null pronoun providing the term of comparison complementing other has the same content as the null pronoun restricting each unless it is linked to the variable bound by each:

$$
\begin{aligned}
& \text { Each other } \Rightarrow \quad\left[\text { Each } x: \operatorname{Pro}_{i}(x)\right] \ldots[1 Y: Y \text { other than } x] \\
& {\left[\text { Each } x: \operatorname{Pro}_{i}(x)\right] \ldots\left[1 Y: Y \text { other than } \operatorname{Pro}_{i}\right] }
\end{aligned}
$$

If that first null pronoun is understood to denote the Eastsiders, then having the second denote the same derives a cross-town mistrust and spares Eastsiders from mistrusting their own kind, as desired. ${ }^{11}$

To reciprocate this mistrust, we will also need the first null pronoun to denote the Westsiders and thus for them to mistrust those other than Westsiders, namely the Eastsiders. If at first one is taken to denote Eastsiders, that's only half the story, in another pass, one should be taken to denote Westsiders. In (122), for example, the antecedent sentences denote separate events, of course- let's suppose that a subsequent sentence can refer back to them collectively, as paraphrased in (133):

(133) Eastsiders chafed. Westsiders seethed. In those events, one insulted the other, each lobbing barbs at the other's privates.

If the reference to those events is then understood distributively-recall the earlier example of conditional clauses, which are definite descriptions then understood distributively - we can fix the content of one so that it denotes appropriately within each event. Consider the paraphrase in (134):

(134) Eastsiders chafed. Westsiders seethed. Those events, in any, the Experiencers in that event insulted the persons in those events other than the Experiencers in that event, each lobbing barbs at the other's privates. 
(135) Eastsiders chafed. Westsiders seethed. [l $E:$ those events] $[\forall e: E e]$ $[\mathrm{l} X$ : Experiencer $[e, X]] \ldots$ insult... $[\mathrm{l} Y:$ Experiencer $[E, Y] \& Y$ other than $[\mathrm{L} X$ : Experiencer $[e, X]]] \ldots$

Those events are the Eastsiders chafing and the Westsiders seething. In any one of them, say, the Eastsiders chafing, the Experiencers in that event, that is, the Eastsiders insulted those among the persons in those events, that is, those among the Eastsiders and Westsiders who are other than those experiencing the chafing, that is, other than the Eastsiders. In other words, the Eastsiders, those who experienced chafing, insulted the Westsiders, those who experienced seething. If, instead, we start with the seething, then according to the paraphrase and the logical form in (135), the Experiencers in that event, that is, the Westsiders, the seethers, insulted everybody else chafing or seething, that is, the chafing Eastsiders. Note in the logical form in (135), that the comparison term that tells us other than who, is exactly the same as the gloss on its antecedent one. In understanding (122), the sense of one and other than one is fixed. The understanding that it is first Eastsiders $v s$. Westsiders and then Westsiders $v s$. Eastsiders is purely an effect of quantifying distributively over the antecedently described events.

Now I argue in Conjunction Reduction Redux that the coordination of DPs is always an illusion - that the likes of (115) is really like (136), where clauses underlie the apparent coordination of DPs:

(136) Eastsiders were Experiencers and Westsiders were Experiencers, those events were mistrust, and in any of those events, each of the Experiencers in that event (mistrusting) the participants other than the Experiencers in that event.

If so, the account repeats itself, showing generally how the reciprocal construction can be understood to assert a cross-town rivalry.

\section{The interaction of descriptive content and event quantification}

My last argument draws on sentences combining the two ways to weaken reciprocals - as time goes by and rivalry cross-town. Eastsiders vs. Westsiders results from an alternation in the event referred to inside the reciprocal's descriptive content, 'each of the ones there' and 'those who were other than the ones there'. If the events referred to can themselves be temporally organized, we also get the temporal weakening in (137), exactly as we have seen earlier in Langendoen's (80).

(137) Six Plantagenets and five Bolingbrokes succeeded each other to the English throne.

(138) * Six Plantagenets succeeded five Bolingbrokes to the English throne, and five Bolingbrokes succeeded six Plantagenets to the English throne. 
Sentence (137) reports the alternation of Plantagenets and Bolingbrokes on the English throne. But, as (138) makes clear, there is no reciprocity between a group of six Plantagenets and a group of five Bolingbrokes. Rather, it's concept reciprocity, so to speak, Plantagenet $v s$. Bolingbroke. The six and the seven were involved in various events of Plantagenet succeeding Bolingbroke and Bolingbroke succeeding Plantagenet. Which Plantagenet and which Bolingbroke is entirely dependent on the event. This comports well with the account on offer, where definite descriptions dependent on events refer to the participants in events. There is never any reference direct to groups covering a domain. The members of such a group are denoted only to the extent that they fall under a description of the participants in an appropriate event. In (137), each other means that for either of the initial two events, the Plantagenets acting or the Bolingbrokes acting, each participant in it succeeds the participants in the initial two events who are other than the participants in the event under discussion and who succeeded to the throne in the circumstances prior to this succession:

$$
\begin{aligned}
& \text { Six Plantagenets were Agents and five Bolingbrokes were Agents \& } \\
& {[\mathrm{l} E: \text { those events }] \text { succeed }[E] \&} \\
& {[1 E: \text { those events }][\forall e: E e]\left[1 E^{\prime}: \text { Overlap }\left[E^{\prime}, e\right]\right]} \\
& {\left[1 X: \text { Agent }\left[E^{\prime}, X\right]\right][\text { Each } x: X x]\left[1 E^{\prime}: \forall e\left(E^{\prime} e \rightarrow E^{\prime} e\right) \& \operatorname{Agent}\left[E^{\prime \prime}, x\right]\right]} \\
& {\left[\exists E^{\prime \prime}: \mathrm{t}\left(E^{\prime \prime}\right) \leq \mathrm{t}\left(E^{\prime}\right)\right]} \\
& {\left[\mathrm{l} Y: \text { Agent }[E, Y] \& Y \text { other than }\left[\mathrm{l} X: \text { Agent }\left[E^{\prime}, X\right]\right] \& \text { Agent }\left[E^{\prime \prime}, Y\right]\right]} \\
& \text { Theme }\left[E^{\prime}, Y\right]
\end{aligned}
$$

'Six Plantagenets were Agents and five Bolingbrokes were Agents, those (two, scattered) events were succession, in each of those events, the Agents in that event each succeeding the Agents, other than the Agents in that event, who had earlier succeeded.'

For example, in the event where six Plantagenets were Agents, the Agents in that event, viz., the six Plantagenets, were such that each succeeded the- Agents other than the Agents in that event-that is, Bolingbrokeswho had earlier succeeded.

The comparison term, other than those in this event, will with the choice of one or the other event, denote either Plantagenets or Bolingbrokes. The further restriction to only those among them who have already succeeded to the throne achieves the desired result that each of the Plantagenets succeeds some Bolingbroke and each of the Bolingbrokes succeeds some Plantagenet. I do not see how else to express both that the reciprocity holds between rival families (rather than rival individuals) and that each of one family need succeed only some of the other as in Langendoen's original examples of weak reciprocity. ${ }^{12}$ 


\section{Conclusion}

So, by way of summary- The reciprocal construction is structurally and lexically unambiguous - as is the conditional - and the reciprocal is a composition of the meaning of each and the meaning of other, as the advocates of (2) suspected all along. The reciprocal construction, like the conditional, is also an adverbial clause. This and the fact that each is a distributive quantifier imposes a certain arrangement of event quantifiers, which fixes the temporal relations among the events described. As a result, both the force of a conditional and a reciprocal are unbounded unless bounded as time goes by. This subsumes several effects, including the earliest observation in (1) contrasting stative and eventive predicates, the effect of temporal orientation even among the eventive predicates, as in (80) vs. (82), and the effect that isolates a local moment of transition, as in (80) and (88) vs. (84) and (87). The adverbial construction and the distribution of event quantifiers is so far just so much logical syntax. The reciprocal constructions in (89) and (94)-(98)-remember the suffocating cockroaches - then show that the distributive each must not include the verb within its scope. Thus the content of the adverbial clause is subatomic (containing thematic relations separated from the host verb) and it denotes proper parts of the events that the matrix clause describes. The divergence between weak reciprocals and collective reflexives in (105)-(110) makes the same point over, under slightly different circumstances. Next, looking within the quantifiers that each and other stand for, each is the restricted each $x$ of the one and it is answered, as in (132), by those other than the one or by those other than $x$. The one is a descriptive anaphor that is itself dependent on events. How we quantify over these events derives the cross-town rivalry and the interaction of this concept reciprocity, as I called it, and the weakening of reciprocity as time goes by, seen in (138).

I have alleged that the reciprocal each other is itself without structural or lexical ambiguity. Of course this is an austerity that indulges the full embrace of event quantification, Davidsonian decomposition and in particular the tokening of subatomic expressions separated from their verbs. If you want a unified analysis of each other, it's being offered with other commitments - to aspects of event semantics that I have urged on you before - and there's no escape from this quid proquo.

\section{Endnotes}

* Many thanks for questions and discussion prior, during and after the conference to Ron Artstein, Chris Barker, Paul Dekker, Kit Fine, Graeme Forbes, Alessandra Giorgi, Jim Higginbotham, Polly Jacobson, Stefan Kaufmann, Chris Kennedy, Richard Larson, Peter Ludlow, Fabio Pianesi, Tanya Reinhart, Ken Safir, Phil Schlenker, Roger Schwarzschild, Anna Szabolcsi, and Karina Wilkinson. Again to Phil Schlenker, for a midnight rescue from certain error, and to Anna Szabolcsi 
and the NYU Organizing Committee, for their kind invitation and for hosting SALT in "the tiara of civilization" (Robert F. Wagner III, City Planning Commission).

${ }^{1}$ Space does not permit discussion of this last point, which is orthogonal to those treated below. An intention to describe several, smaller events each of which satisfies reciprocity where a large, single event would fail to is responsible for the weaker truth conditions in the following: $A$ thousand thespians collaborated on rival productions. The plates are stacked on top of each other in three separate stacks.

${ }^{2}$ That if-clauses denote events, see Lycan 1984, 1991.

${ }^{3}$ Structure internal to 'ceteris-paribus(e,e")' (see following note) will derive the failure of antecedent strengthening observed in (45)-(49).

4, 5, 8-10,12 Notes in the unabridged version at www-rcf.usc.edu/ schein/adr.pdf or semanticsarchive.net/Archive/2UyZWU4M/schein.salt11.pdf.

${ }^{6}$ Rather than an episodic event, the sentences (4) and (73)-(76) may report an objective state holding of current conditions, in which the temporal dimension is realized, so I must assume, in the perspective or epistemic stance adopted by the speaker. As is well known, progressive aspect shows a similar effect. In many a neutral context, it is infelicitous to say "Interstate 80 is leading to the George Washington Bridge," the naked facts about road and bridge failing to satisfy the conditions for progressive aspect. Yet, the sentence becomes felicitous as I am driving east towards home, not because of any change in the objective condition of the participants, but because the surrounding conditions of observation meet the requirements for progressive aspect. But, then it is also enough for my finger to be tracing out Interstate 80 on a map, or to do so, as I often do, with the mind's eye, wherever I may be. Likewise, plates are stacked and freeway exits spaced. ${ }^{7}$ Fiengo \& Lasnik (1973: 450f.) make the point contrasting Each of the cars bumped into the other and The cars bumped into each other.

${ }^{11}$ That the two null pronouns denote the same things may be a residual fact about reciprocals that I will have to stipulate as such; or perhaps for independent reasons, two proximate, unpronounced, unstressed and therefore non-contrastive pronouns have little hope of referring to different things.

\section{References}

C. Barker. 1993. A presuppositional account of proportional ambiguity. SALT III, 1-18.

C. Barker. 1996. Presuppositions for proportional quantifiers. NALS 4.3: 237-259.

S. J. Barker. 1997. E-type pronouns, DRT, dynamic semantics and the quantifier/variable-binding model. $L \& P$ 20.2:195-228.

G. Boolos. 1985. Nominalist Platonism. The Philosophical Review 94: 327-344.

L. Carlson. 1982. Plural quantifiers and informational independence. Acta Philoso phica Fennica 35: 163-174. 
M. Dalrymple, I. Hayrapetian and T. H. King. 1998. The semantics of the Russian comitative construction. NLLT 16.3: 597-631.

M. Dalrymple, M. Kanazawa, Y. Kim, S. Mchombo \& S. Peters. 1998. Reciprocal expressions and the concept of reciprocity. $L \& P$ 21.2: 159-210.

M. Davies. 1991. Acts and scenes. In N. Cooper \& P. Engel, eds., New Inquiries into Meaning and Truth, 41-82. NY: St. Martin's Press.

R. C. Dougherty. 1974. The syntax and semantics of each other constructions. Foundations of Language 12: 1-47.

G. Evans. 1977. Pronouns, quantifiers and relative clauses (I). Canadian Journal of Philosophy 7.3: 467-536.

G. Evans. 1980. Pronouns. LI 11.2: 337-362.

R. W. Fiengo \& H. Lasnik. 1973. The logical structure of reciprocal sentences in English. Foundations of Language 9: 447-468.

E. Garrett. 1998. Weak readings: another case of apparent uniqueness violations. ms. UCLA.

M. Geis. 1973. If and unless. In B. J. Kachnu, et al. eds., Issues in Linguistics: Papers in Honor of Henry and Renee Kahane, 231-253. Urbana and Chicago: University of Illinois Press.

I. Heim. 1982. The semantics of definite and indefinite Noun Phrases. $\mathrm{PhD}$ UMass, Amherst.

I. Heim. 1984. A note on negative polarity and downward-entailingness. NELS 14, 98-107.

I. Heim, H. Lasnik \& R. May. 1991. Reciprocity and plurality. LI 22.1: 63-101.

J. J. Katz. 1977. Propositional Structure and Illocutionary Force: A Study of the Contribution of Sentence Meaning to Speech Acts. Harvard University Press.

D. T. Langendoen. 1978. The logic of reciprocity. LI 9.2: 177-197.

W. G. Lycan. 1984. A syntactically motivated theory of conditionals. In P. French, T. E. Uehling \& H. Wettstein, eds., Midwest Studies in Philosophy IX: Causation and Causal Theories. Minneapolis: University of Minnesota Press.

W. G. Lycan. 1991. Even and even if. L\&P 14.2: 115-150.

J. D. McCawley. 1981. Everything that Linguists Have Always Wanted to Know About Logic**but were ashamed to ask. Chicago: University of Chicago Press.

B. Schein. 1993. Plurals and Events. Cambridge: MIT Press.

B. Schein. 1997. Conjunction Reduction Redux. ms. USC. www-rcf.usc.edu/ schein/crrchap1.pdf

L. K. Schubert \& F. J. Pelletier. 1989. Generically speaking, or, using Discourse Representation Theory to interpret generics. In G. Chierchia, B. H. Partee \& R. Turner, eds., Properties, Types and Meaning. Vol. II: Semantic Issues, 193-268. Dordrecht: Kluwer.

R. Stalnaker. 1968. A theory of conditionals. From Studies in Logical Theory, American Philosophical Quarterly, Monograph: 2, 98-112.

B. Taylor. 1985. Modes of Occurrence. Oxford: Basil Blackwell. 